\title{
Production of Ready-to-Reconstitute Functional Beverages by Utilizing Whey Protein Hydrolysates and Probiotics
}

\author{
Sabbini Kalyan Kumar, Heddur Manjappa Jayaprakasha, Hyun-Dong Paik ${ }^{1}$, Soo-Ki Kim¹, \\ Song Ee Han ${ }^{1}$, A-Ram Jeong ${ }^{1}$, and Yoh Chang Yoon ${ }^{1 *}$ \\ Department of Dairy Technology, Dairy Science College, KVAFSU, Hebbal, Bangalore 560024, India \\ ${ }^{1}$ Division of Animal Life Science, Konkuk University, Seoul 143-701, Korea
}

\begin{abstract}
This investigation was aimed at developing a ready-to-reconstitute beverage by utilizing probiotics and whey protein hydrolysates carrying bioactive peptides. Cheddar cheese whey was ultrafiltered. The $18 \%$ protein retentate was subjected to protein hydrolysis using Neutrase. The hydrolyzed retentate was further condensed to $35 \%$ total solids and spray-dried at $75^{\circ} \mathrm{C}$ outlet air temperature. Different levels of sugar, citric acid and stabilizer were blended for spray-dried hydrolysates. Spray-dried hydrolysate was further inoculated with different levels of probiotics grown in a whey medium and dried in fluidized-bed drier at $40^{\circ} \mathrm{C}$ to obtain a ready-to-reconstitute beverage. Hydrolysis was greatest at an enzyme:substrate ratio of $1: 25$ for $3 \mathrm{~h}$. Spray-dried hydrolysate reconstituted to $1 \%$ protein and blended with $15 \%$ sugar, $0.2 \%$ citric acid and $0.15 \%$ xantham gum resulted in a superior product with no sedimentation. Accordingly, sugar, citric acid and xanthum gum were dry-blended with spray-dried hydrolysates. Bifidobacterium bifidum and Lactobacillus acidophilus that was grown separately in a whey medium, blended to produce $2 \%$ spray-dried hydrolysate and dried as described above resulted in a readyto-reconstitute beverage mix. The fluidized dried product typically exhibited a probiotic count of $10^{8}$ colony forming units $(\mathrm{CFU}) / \mathrm{g}$. However, blending of probiotic to the retentate and direct spray-drying precipitously reduced the probiotic count to $10^{4} \mathrm{CFU} / \mathrm{g}$ of powder.
\end{abstract}

Key words: whey, ultrafiltration, whey protein concentrate, protein hydrolysate, spray drying, fluidized bed drying, bioactive peptide, probiotics

\section{Introduction}

Whey components are used as potential food ingredients in a variety of foods due to their excellent nutritional and promising functional properties (Jayaprakasha and Brueckner, 1999). By virtue of their higher proportion of essential amino acids, the biological value of these proteins is higher as compared to that of other dietary proteins (Renner, 1983). Whey protein concentrate (WPC) with varying protein content and composition can be obtained by monitoring the ultrafiltration of whey (Jayaprakasha and Yoon, 2005). WPC by itself has certain inherent bioactivities that can be further nurtured and enhanced by enzymatic hydrolysis as a result of a broad spectrum of peptides and amino acids (Jayaprakasha and Yoon, 2005a; Nielsen and Turner, 1992). Some of these

*Corresponding author: Yoh Chang Yoon, Division of Animal Life Science, Konkuk University, Seoul 143-701, Korea. Tel: 82-2-450-3692, Fax: 82-2-458-7305, E-mail: ychyoon@konkuk. ac. $\mathrm{kr}$ bioactive peptides are known to carry several health benefits (Anne and Leppale, 2001). Since WPC carries high levels of branched chain amino acids and its hydrolysate carries several bioactive peptides, it is considered useful in formulation beverages. Such beverages can have extensive applications for growing children, athletes, weight loss, and geriatric foods (Anssi, 2004; Huffman, 1996; McIntosh et al., 1998). The solubility of whey protein concentrate at low $\mathrm{pH}$ is a unique property that allows it to function in acidic foods and beverages. Thus, it has great potential as a food ingredient for the protein enrichment of soft drinks and beverages (Neilson and Turner, 1992). Similarly, probiotics are organisms that upon ingestion in certain numbers exert certain health benefits in a host beyond inherent basic nutrition (Schaafsman, 1996). Bifidobacteria and other probiotic bacteria are known to provide a number of health benefits, and more than 90 products containing one or more groups of probiotics are available worldwide (Terry et al., 2004; Thamaraj and Shah, 2003). Several of the potential health benefits are scientifically well established and probiotics are cur- 
rently being used in several health food formulations (Giridhari and Gosh, 2006; Ouwehend et al., 2003). In view of the potential nutritional and health benefits of whey protein-based bioactive peptides and probiotics, our endeavor in this study was to develop a ready-to-reconstitute product that can be used by all segments of the population. These aspects are of great economic value in the dairy industry for adding value to, and effective utilizing, by-products.

\section{Materials and Methods}

\section{Processing of whey by ultrafiltration}

Fresh cheddar cheese whey was processed using spiral wound membrane-type ultrafiltration (equipped with a polysulphone membrane having a $1.8 \mathrm{~m}^{2}$ area and a molecular weight cut off value of $20 \mathrm{kDa}$ ) as per the procedure outlined by Jayaprakasha (1992). Ultrafiltration and diafiltration were continued until the retentate attained $25 \%$ total solids comprised of $18 \%$ protein.

\section{Enzymatic hydrolysis of whey protein concentrate}

The processed retentate was subjected to enzymatic hydrolysis as per the procedure described by Shobha (2002) by adding Neutrase enzyme (Novo Nordisk, Mumbai, India) at enzyme to substrate ratios of 1:25, 1:50, and $1: 100$, and then incubated at $\mathrm{pH} 7.0$ and $40^{\circ} \mathrm{C}$. The degree of hydrolysis $(\mathrm{DH})$ was measured at regular intervals of $30 \mathrm{~min}$ by the $\mathrm{pH}$ state method (Adler-Nissen, 1986). The enzyme to substrate ratio that resulted in maximum hydrolysis in a minimum incubation period was further used for WPC hydrolysis.

\section{Condensing and spray drying of whey protein hydrolysates}

The ultrafiltered whey retentate, which was ezymatically hydrolysed as presented above, was further vacuum concentrated in a single effect evaporator at $54^{\circ} \mathrm{C}$ and 630 $\mathrm{mm} \mathrm{Hg}$ vacuum (Copenhagen, Denmark with a water evaporation capacity of $35 \mathrm{~kg} / \mathrm{h}$ ) to obtain total solids of $35 \%$ in the retentate. In addition, the retentate was spraydried using an Anhydro spray drier (Anhydro, Copenhagen, Denmark, consisting of centrifugal automizer and electrical heating system with a water evaporation capacity of $7 \mathrm{~kg} / \mathrm{h}$ ) at an outlet air temperature of $75^{\circ} \mathrm{C}$ by monitoring the feed flow rate of the drier (Yoo et al., 2009). This spray-dried hydrolysate was further used to prepare ready-to-reconstitute beverage mixes.

\section{Optimization of sugar level for beverage prepara- tion}

To determine the level of sugar to be blended with the dried hydrolysate, the spray-dried WPC hydrolysate was reconstituted to have protein levels of $0.5,1.0,1.5$, and $2.0 \%$ and blended with various levels of sugar $(10,12$, 14,15 , and $16 \%$ ) and then served to an in-house panel of judges to determine the best levels of protein and sugar in the beverage mix by scoring the beverages on a 9-point Hedonic scale for overall acceptability.

\section{Optimization of sugar and citric acid levels in the beverage}

The whey protein hydrolysate, reconstituted to have an optimum protein level, was blended with various combinations of citric acid $(0.1,0.2$, and 0.3$)$ and amounts of sugar $(10,12,14,15$, and $16 \%)$. These combinations were served to a panel of judges to determine the best levels of sugar and citric acid in the beverage mix by scoring on a 9-point Hedonic scale. The proportion of sugar and citric acid to be blended with the spray-dried hydrolysate was computed based on the results.

\section{Optimization of stabilizer level in the beverage}

The spray-dried whey protein hydrolysate that was dry blended with optimum levels of sugar and citric acid was reconstituted to have various levels of protein $(0.5,1.0$, 1.5 , and $2.0 \%$ ), and then xantham gum stabilizer (procured from Lucid Colloids Ltd, Jodhpur, brand name Stamulcol ULV-1000) was added at 0.05, 0.10, 0.15, 0.20, and $0.25 \%$ levels. These reconstituted beverages were kept undisturbed for a period of $1 \mathrm{~h}$ and visible observations were made for the extent of sedimentation in each sample. The optimum level of stabilizer to be blended into the dried product was computed based on the observations and the prevention of sedimentation upon reconstitution of the powder.

\section{Optimization of additions of probiotic cultures to the spray-dried hydrolysates}

Freeze-dried probiotic cultures, namely Lactobacillus acidophilus LA-5 and Bifidobacterium BB-12, were procured from the Mumbai branch of Chr. Hansen Pvt Ltd., Denmark. These were subcultured and maintained in the laboratory.

These cultures were grown separately in a sterilized whey medium by inoculating at different levels. In the case of Bifidobacterium BB-12, anaerobic conditions were created by subjecting the whey medium flasks inoc- 
ulated with the organism to vacuum treatment by employing a laboratory model vacuum pump. Growth was monitored by incubating at $38^{\circ} \mathrm{C}$ for a maximum period of $21 \mathrm{~h}$. However, the best results were obtained by $15 \mathrm{~h}$ of incubation, and thus the same protocol was used in further experiments.

The cultures that were grown separately in sterilized whey medium at different inoculum levels were incorporated into the hydrolysed WPC mix before spray drying, and then the viabilities retained after spray drying were enumerated. In addition, the spray-dried whey protein hydrolysate was dry blended with determined quantities of sugar, citric acid, and xantham gum stabilizer. Similarly, a known weight amount of the spray-dried hydrolysate was placed in a fluid bed drier and wet blended with Bifidobacterium BB-12 culture at levels of 4, 5, and 6\%. Similarly, Lactobacillus acidophilus LA-5 was also added at 4,5 , and $6 \%$ levels. The wetted product was redried in a fluid bed drier (GMP model fluid bed drier, supplied by Milk Tech Engineers, India, capacity $2 \mathrm{~kg}$ wet material per batch) by maintaining an outlet temperature of $40^{\circ} \mathrm{C}$. The fluid bed dried product was enumerated for the individual Lactobacillus acidophilus LA-5 and Bifidobacterium BB-12 populations by using culture specific selective media. Anaerobic conditions were created for the enumeration of Bifidobacterium BB-12 using the candle method by following the procedure outlined in Laboratory Methods in Food Microbiology-Edition III.

\section{Sensory evaluation}

The beverages were prepared from ready-to-reconstitute mixes by reconstituting the powder by placing $165 \mathrm{~g}$ of dried product into $1000 \mathrm{~mL}$ of potable water. The beverages were then served to an in-house panel of judges for sensory evaluations to score the beverages with respect to various sensory characteristics on a nine point Hedonic scale. The awarded scores were compiled and statistically analyzed.

\section{Statistical analysis}

The entire results were statistically analyzed to test for significance using ANOVA in a completely randomized design. The level of significance used for all experiments was $5 \%(p<0.05)$.

\section{Results and Discussion}

\section{Process optimization for enzymatic hydrolysis}

Among the three levels of E:S ratios attempted, the extent of hydrolysis attained at the 1:25 ratio was significantly higher as compared to $1: 50$ and 1:100. By increasing the concentration of Neutrase enzyme from 1:100 to $1: 25$, the extent of hydrolysis attained increased significantly at all durations of hydrolysis. Similarly, with increased duration of incubation, there was a significant increase in the degree of hydrolysis up to $180 \mathrm{~min}$. However, there was no significant improvement with a further prolonged duration of hydrolysis. After $3 \mathrm{~h}$ of incubation, the extents of hydrolysis attained were 6.67, 5.50, and $5.12 \%$ for the utilized $E: S$ ratios of $1: 25,1: 50$, and $1: 100$, respectively (Table 1 ). The enzyme to substrate ratio was found to have a significant effect on the degree of hydrolysis, irrespective of the duration of hydrolysis. The results of this investigation are well supported by the report of Adler-Nissen (1986). Shobha (2002) attained a maximum $8 \% \mathrm{DH}$ at an $\mathrm{E}: \mathrm{S}$ ratio of $1: 25$ after $5 \mathrm{~h}$ of incubation at $40^{\circ} \mathrm{C}$.

\section{Effects of different protein levels on acceptability of beverages prepared from hydrolyzed WPC}

The spray-dried WPC hydrolysate was reconstituted to protein levels of $0.5,1.0,1.5$, and $2.0 \%$ and admixed with various levels of sugar $(10,12,14,15$, and 16\%). Among the different protein levels examined, the beverage prepared from $1.0 \%$ protein was found to be superior as compared to higher levels of protein (1.5 and 2.0\%). By increasing the protein level above $1.0 \%$, there was a significant decrease in overall acceptability scores (Table 2). The overall acceptability scores awarded to the beverages prepared from $0.5,1.0,1.5$, and $2.0 \%$ hydrolysed WPC at the $15 \%$ sugar level were 7.60, 7.78, 7.52, and 7.20, respectively. The decreased mean scores with increased

Table 1. Effects of enzyme to substrate ratios (E:S) and duration of incubation on extent of WPC hydrolysis*

\begin{tabular}{ccccc}
\hline \hline \multirow{2}{*}{$\begin{array}{c}\text { Time } \\
(\min )\end{array}$} & $1: 25$ & $1: 50$ & $1: 100$ & CD \\
\cline { 2 - 4 } 20 & 4.14 & 3.87 & 3.39 & \\
40 & 4.55 & 4.29 & 3.81 & \\
60 & 5.01 & 4.53 & 4.07 & \\
90 & 5.83 & 4.80 & 4.39 & \\
120 & 6.08 & 5.04 & 4.66 & \\
150 & 6.34 & 5.29 & 4.90 & \\
180 & 6.67 & 5.50 & 5.12 & \\
240 & 6.69 & 5.59 & 5.18 & \\
\hline CD & & \multicolumn{3}{c}{0.243} \\
\hline
\end{tabular}

*Average of three trials.

$\mathrm{CD}$ : critical difference at $5 \%$ level of significance.

Neutrase enzyme at $\mathrm{pH} 7.0$ and temperature $40^{\circ} \mathrm{C}$. 
Table 2. Effects of protein and sugar levels on overall acceptability of reconstituted beverages*

\begin{tabular}{clllll}
\hline \hline \multirow{2}{*}{$\begin{array}{c}\text { Protein } \\
\text { level (\%) }\end{array}$} & \multicolumn{5}{c}{ Sugar level (\%) } \\
\cline { 2 - 6 } & 10.0 & 12.0 & 14.0 & 15.0 & 16.0 \\
\cline { 2 - 6 } Overall acceptability sensory scores** \\
\hline 0.5 & 6.90 & 7.20 & 7.40 & 7.60 & 7.50 \\
1.0 & 7.10 & 7.38 & 7.54 & 7.78 & 7.70 \\
1.5 & 6.60 & 7.05 & 7.25 & 7.52 & 7.40 \\
2.0 & 5.67 & 6.85 & 7.09 & 7.20 & 7.00 \\
CD & 0.232 & 0.252 & 0.245 & 0.239 & 0.220 \\
\hline
\end{tabular}

*Average of three trials.

** Scores on 9 point hedonic scale.

levels of protein in the beverage are mainly attributed to increased levels of bitterness as a result of higher proportions of bitter peptides. Similar observations were made by Shashikala (2000) and Shobha (2002) when whey protein was hydrolysed using trypsin and Neutrase enzymes, respectively. Mean scores for overall acceptability increased up to the $1.0 \%$ protein level and thereafter they decreased significantly. Singh et al. (1994) recommended a $0.30 \%$ protein concentration for a whey guava beverage formulation. Shashikala (2000) used trypsin hydrolysed WPC at 1 to $3 \%$ protein concentrations to prepare different flavoured beverages. Shobha (2002) optimized the protein level of a hydrolysed WPC beverage at $1.0 \%$ and attained satisfactory scores for various sensory attributes.

\section{Effects of sugar and citric acid levels on overall acceptability of reconstituted beverages}

The spray-dried whey protein hydrolysate was reconstituted to the $1.0 \%$ protein level and blended with different levels of sugar and citric acid. The scores pertaining to the beverages prepared from various levels of sugar (10, $12,14,15$, and $16 \%)$ and citric acid $(0.1,0.25$, and $0.3 \%)$

Table 3. Effects of sugar and citric acid levels on overall acceptability of reconstituted beverages*

\begin{tabular}{ccccc}
\hline \hline \multirow{2}{*}{$\begin{array}{c}\text { Sugar } \\
(\%)\end{array}$} & \multicolumn{3}{c}{ Citric acid (\%) } \\
\cline { 2 - 3 } & 0.1 & 0.20 & 0.30 & \\
\cline { 2 - 3 } & Overall acceptability sensory scores** & \\
\hline 10 & 7.12 & 7.50 & 7.44 & \\
12 & 7.32 & 7.71 & 7.63 & 0.163 \\
14 & 7.53 & 7.93 & 7.84 & \\
15 & 7.90 & 8.14 & 8.06 & \\
16 & 7.64 & 8.01 & 7.92 & \\
\hline CD & \multicolumn{5}{c}{0.189}
\end{tabular}

*Average of three trials.

**Scores on 9 point hedonic scale. are presented in Table 3. It is evident from the results that there were significant improvements in scores up to the $15 \%$ sugar level, and thereafter scores for overall acceptability decreased. The amount of required sugar varied significantly with the level of citric acid added. As the citric acid level in the beverage increased, respective overall acceptability scores increased up to the $0.20 \%$ citric acid level and thereafter significantly decreased. The beverage prepared from $15 \%$ sugar and $0.20 \%$ citric acid received the highest overall acceptability score of 8.14 as compared to the other combinations.

The obtained results are comparable to those of Shobha (2002) who used $16 \%$ sugar and $0.4 \%$ citric acid in a hydrolysed protein beverage. The addition of $0.2 \%$ citric acid reportedly resulted in superior quality whey based fruit beverages (Sharada Devi et al., 2004). Khamrui and Rajhoria (1998) reported that ready-to-serve drinks usually contain up to $14 \%$ sugar. The preferred higher amount of sugar in this investigation can be mainly ascribed to the bitterness attained as a result of hydrolysis.

\section{Effects of stabilizer on sedimentation in reconsti- tuted beverages}

The effects of various levels of xanthan gum on sedimentation in beverages prepared at $0.5,1.0,1.5,2.0 \%$ protein levels are presented in Table 4. It is evident from the results there was no sedimentation in the reconstituted beverages prepared with 0.50 and $1.0 \%$ protein when 0.15 and $0.20 \%$ levels of stabilizer were added, respectively. To prepare an acceptable beverage without sedimentation, additions of colloidal stabilizers such as pectin, sodium alginate, carrageenan, CMC, guar gum, etc. are recommended at levels of $0.05-0.10 \%$ (Khamrui and Rajhoria, 1998). In the present investigation, the bev-

Table 4. Effects of stabilizer levels on sedimentation in reconstituted beverages

\begin{tabular}{|c|c|c|c|c|}
\hline \multirow{3}{*}{$\begin{array}{c}\text { Stabilizer } \\
(\%)\end{array}$} & \multicolumn{4}{|c|}{ Protein $(\%)$} \\
\hline & 0.5 & 1.0 & 1.5 & 2.0 \\
\hline & \multicolumn{4}{|c|}{ Extent of sedimentation } \\
\hline 0.05 & ++ & ++ & ++++ & ++++ \\
\hline 0.10 & + & + & +++ & +++ \\
\hline 0.15 & - & - & ++ & ++ \\
\hline 0.20 & - & - & + & + \\
\hline
\end{tabular}

++++ : High sediment.

+++ : Medium sediment.

++ : Low sediment.

+ : Insignificant.

$-:$ Nil. 
Table 5. Effects of drying techniques on viability of probiotic cultures*

\begin{tabular}{cccccc}
\hline \hline \multirow{2}{*}{$\begin{array}{c}\text { Culture } \\
\text { level } \\
(\%)\end{array}$} & \multicolumn{2}{c}{ LA } & \multicolumn{2}{c}{ BB } \\
\cline { 2 - 3 } \cline { 5 - 6 } & Spray dried & Fluid bed dried & & Spray dried & Fluid bed dried \\
\hline 4 & 4.49 & 8.64 & & \multicolumn{4}{c}{ Viability } & $(\log$ CFU/g) \\
5 & 4.67 & 8.83 & & 4.32 & 8.22 \\
6 & 4.72 & 8.91 & & 4.38 & 8.65 \\
$\mathrm{CD}$ & 0.09 & 0.12 & & 0.14 & 0.178 \\
\hline
\end{tabular}

*Average of three trials.

LA: Lactobacillus acidophilus.

BB: Bifidobacterium bifidum.

erage prepared with $1.0 \%$ protein and $0.15 \%$ stabilizer was found to be highly acceptable since it had good consistency and no sedimentation as compared to the other combinations.

\section{Effects of inoculum amount and drying techniques on viability of probiotics in dried whey protein hydrolysates}

The viabilities of LA-5 and BB-12 as affected by the type of drying and level of inoculation are presented in Table 5. As seen in the table, inoculation level had no significant effect on the viabilities of LA-5 and BB-12. However, the type of drying had a significant effect on viability. The viability of LA-5 in the spray-dried sample was $4.49 \log \mathrm{CFU} / \mathrm{g}$, whereas in the fluid bed dried product it was nearly double (8.64 log CFU/g). Similarly, the viable count of BB-12 in the spray-dried product was $4.18 \log \mathrm{CFU} / \mathrm{g}$ versus $8.22 \log \mathrm{CFU} / \mathrm{g}$ for the fluid bed dried product, indicating the severe adverse effects of spray drying on the viabilities of both LA-5 and BB-12. Similar observations of spray-dried cultures were made by several other researchers. Gardiner et al. (2000) demonstrated that a culture of $L$. paracasei NFBC-338 spraydried at an outlet temperature of $80-85^{\circ} \mathrm{C}$ had a survival rate of only $49 \%$. Simpson (2005) examined the tolerance of various species of the genus bifidobacterium to heat and oxygen in selected strains during spray drying and reported that spray drying followed by fluidized bed drying greatly improved viability.

\section{Sensory properties of beverages prepared from probiotic-enriched beverage mixes}

Ready-to-reconstitute beverage mixes prepared with and without LA-5 and BB-12 cultures were reconstituted and served to a panel of judges in order to assess various sensory attributes of the beverages. The results are presented in Table 6. It is evident from the results that all three types of beverages were highly acceptable and received scores of more than 7.75 for all or most of sensory attributes. The overall acceptability scores awarded to the LA-5 and BB-12 culture-carrying beverages were 7.82 and 7.84, respectively, whereas the score for the plain whey protein hydrolysed beverage was 8.14 , indicating that this beverage was slightly more preferred. However, such studies pertaining to whey protein hydrolysate- and probiotic-based beverages are limited, as noted from the literature. The flow diagram for preparation of the readyto-reconstitute beverage mixes is represented in Fig. 1.

In this investigation, a method of formulation was developed for a ready-to-reconstitute beverage by utilizing a combination of whey protein hydrolysate carrying bioactive peptides along with probiotics. Whey can be ultrafiltered and diafiltered to recover whey proteins in their native form as whey protein concentrate (WPC). WPC can be further enzymatically hydrolyzed by Neutrase enzyme to obtain whey protein hydrolysate carrying bioactive peptides. In this study, hydrolysates were vacuum condensed and spray-dried, followed by dry blending with known quantities of sugar, citric acid, and stabilizer. Furthermore, the dried product was wet blended with probiotics followed by drying in a fluidized bed drier to obtain a ready-to-reconstitute beverage mix. Since such products contain nutritionally superior whey protein and bioactive peptides as well as probiotics, they have potential use in health beverages. Given the inherent health

Table 6. Sensory characteristics of beverages prepared from ready-to-reconstitute beverage mixes*

\begin{tabular}{lcccc}
\hline \multicolumn{1}{c}{ Type of beverage appearance } & Color \& acceptability & Flavor & Consistency & Overall acceptability \\
\hline Plain WPC hydrolysed beverage & 7.85 & 7.90 & 7.98 & 8.14 \\
WPC hydrolysed beverage with LA culture & 7.82 & 7.79 & 7.92 & 7.82 \\
WPC hydrolysed beverage with BB culture & 7.88 & 7.83 & 7.90 & 7.84 \\
CD & 0.12 & 0.09 & 0.14 & 0.07 \\
\hline
\end{tabular}

*Average of three trials.

Protein concentration: $1 \%$.

Sensory scores on 9 point hedonic scale. 


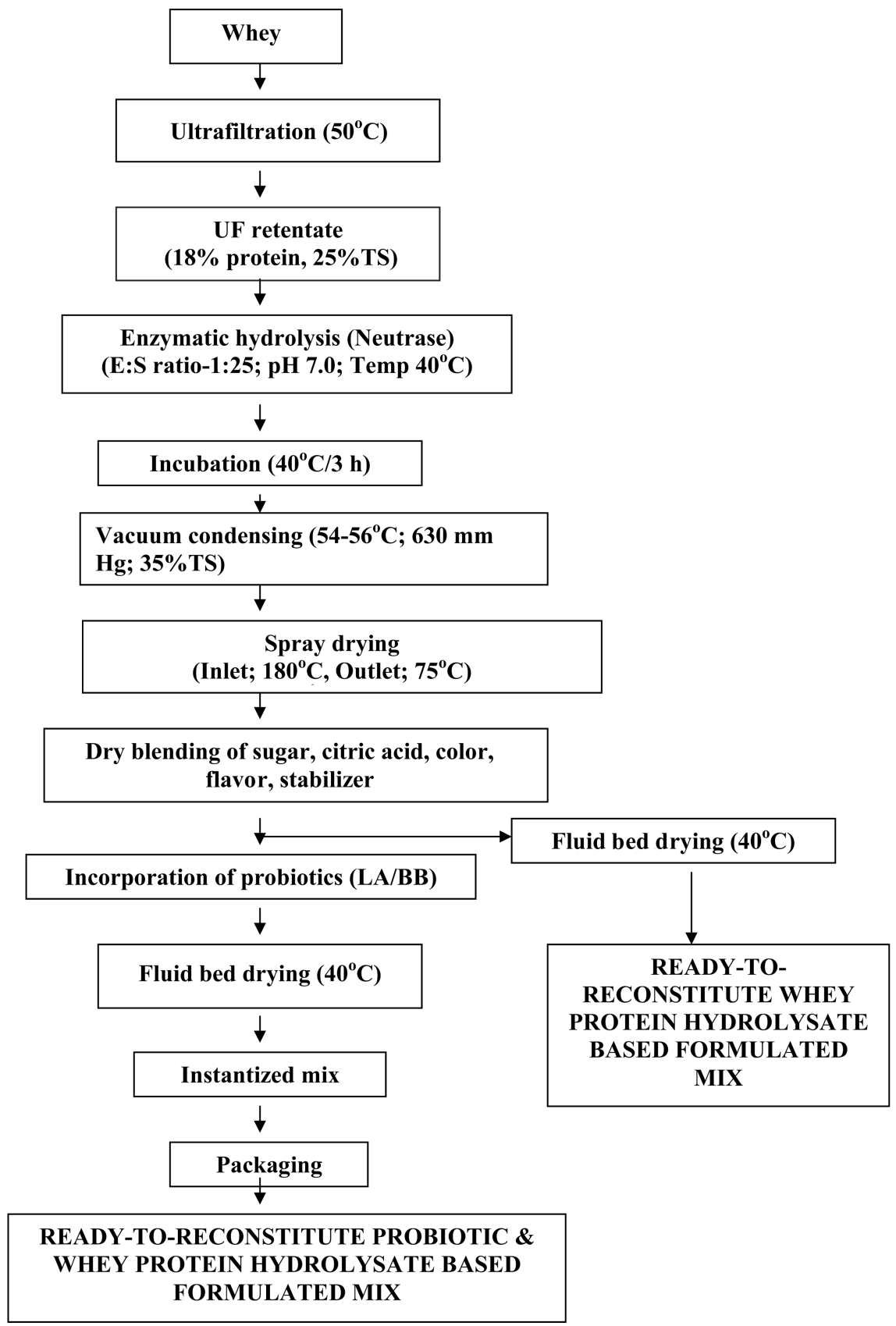

Fig. 1. Flow diagram for preparation of ready-to-reconstitute beverage mixes.

benefits of bioactive peptides and probiotics, there will be great demand for such types of products from all segments of the population. With increasing awareness toward illness and consciousness to health, potential large spanning markets exit all over the globe for these types of ready-to-reconstitute functional beverages.

\section{Acknowledgement}

This research was supported by the Technology Development Program for Food, Ministry for Food, Agricul- ture, Forestry, and Fisheries, Republic of Korea.

\section{References}

1. Adler-Nissen, J. (1986) Some functional aspects of food protein hydrolysates in enzymatic hydrolysis of food proteins. Elseivier Applied Science Pub., NY, pp. 9-24.

2. Boylston, T. D., Vinderola, C. G., Godusi, H. B., and Reinheimer, J. A. (2004) Incorporation of bifidobacteria into cheeses: Challenges and rewards. Intl. Dairy J. 14, 375-387.

3. Gardiner, G. E., O' Sullivan, E., Kelly, J., Auty, M. A. E., Fitzgerald, G. F., Collins, J. K., Ross, R. P., and Stanton, C. 
(2000) Comparative survival rates of human-derived probiotic Lactobacillus paracasei and Lb. salivarius strains during heat treatment and spray drying. Appl. Environ. Microbiol. 66, 2605-2612.

4. Giridhari, S. and Gosh, B. C. (2006) Probiotic dairy foods and prebiotics for health benefit. Indian Food Ind. 25, 68-73.

5. Huffman, L. M. (1996) Processing whey protein for use as a food ingredient. Food Technol. 50, 49-52.

6. Jayaprakasha, H. M. and Yoon (2005) Production of whey protein concentrate by monitoring the process of ultrafiltration. Asian Aus. J. Anim. Sci. 18, 433-438.

7. Jayaprakasha, H. M. and Yoon, Y. C. (2005a) Characterization of physicochemical and functional behavior of enzymatically modified spray dried whey protein concentrate. Milchwissenschaft 60, 305-309.

8. Jayaprakasha, H. M. and Brueckner, H. (1999) Whey protein concentrate: A potential functional ingredient for food industry. J. Food Sci. Technol. 36, 189-204.

9. Jayaprakasha, H. M. (1992) Membrane processing application for production of whey powder and whey protein concentrates. Ph.D. thesis, NDRI, Deemed University, Karnal, India.

10. Khamrui, K. and Rajhoria, G. S. (1998) Making profits from whey. Indian Dairyman 50, 13-17.

11. Manninen, A. H. (2004) Protein hydrolysates in sports and exercise: A brief review. J. Sport. Sci. Med. 3, 60-63.

12. McIntosh, G. H., Royle, P. J., Le Leu, R. K., Regester, G. O., Johnson, M. A., Grinsted, R. L., Kenward, R. S., and Smithers, G. W. (1998) Whey proteins as functional food ingredients. Int. Dairy J. 8, 425-434.

13. Nielsen, W. K. and Turner, A. (1992) Membrane filtration technology. Food Technol. Int. Europe 99-102.

14. Pihlanto-Leppälä, A. (2001) Bioactive peptides derived from bovine whey proteins: 0poid and ace-inhibitory peptides. Trends Food Sci. Technol. 11, 347-356.

15. Prendergast, K. (1985) Whey drinks-technology, processing and marketing, J. Soc. Dairy Technol. 38, 103-105.

16. Renner, E. (1983) Milk and dairy products in human nutrition. Volksw, Verlag, Munchen.

17. Schaafsman, G. (1996) State of the art concerning the probiotic strains in milk products. IDF Nutr. Newslett 55, pp. 2324.

18. Simpson, P. J., Stanton, C., Fitzgerald, G. F., and Ross, R. P. (2005) Intrinsic tolerance of bifidobacterium species to heat and oxygen \& survival following spray drying \& storage. $J$. Appl. Microbiol. 99, 493-501.

19. Sharada Devi, M. S, Banumathi, P., and Jothy, N. (2004) Studies on development and evaluation of whey based fruit beverages. Bev. Food World 11, 44-46.

20. Shashikala, R. (2000) Evaluation of physico-chemical and functional characteristics of enzymatically modified whey protein concentrate and its application in beverages. M.Sc. thesis, UAS, Bangalore.

21. Shobha, K. P. (2002) Process optimization for production of WPC hydrolysates and its applications in ready to use beverages, M.Sc, Thesis, UAS, Bangalore.

22. Sundaraj, N., Nagaraju, S., Venkataraman, M. N., and Jaganath, N. K. (1972) Design and analysis of field experiments. Univer. Agri. Sci., Bangalore.

23. Thamaraj, N. and Shah, N. P. (2003) Selective enumeration of Lactobacillus delbrueckii ssp. bulgaricus, Streptococcus thermophilus, Lactobacillus acidophilus, Bifidobacteria, Lactobacillus casei, Lactobacillus rhamnoous and Propionobacteria. J. Dairy Sci. 86, 2288-2296.

24. Ouwehand, A. C., Bianchi, S. B., Fonden, R., Mogensen, S., and Salminen, S. (2003) Int. Dairy Fed. 380, 4-19.

25. Yoo, S. H. Jayaprakasha, H. M., Lee, S. Y., Palk, H.-D., and Yoon, Y. C. (2009) Effects of processing parameters of spray drying on some of the quality attributes of whey protein concentrate hydrolysates. Milk Sci. Intl. 64, 78-81.

(Received 2010.1.20/Revised 2010.6.9/Accepted 2010.6.18) 